\title{
Article \\ Display of Microbial Glucose Dehydrogenase and Cholesterol Oxidase on the Yeast Cell Surface for the Detection of Blood Biochemical Parameters
}

\author{
Shiyao Zhao ${ }^{1,+}{ }^{+}$Dong Guo ${ }^{2,+}$, Quanchao Zhu ${ }^{1}$, Weiwang Dou ${ }^{1}$ and Wenjun Guan ${ }^{1, *}$ \\ 1 Institute of Pharmaceutical Biotechnology and the Children's Hospital, Zhejiang University School of \\ Medicine, Hangzhou 310012, China; zhaoshiyao@zju.edu.cn (S.Z.); 11818296@zju.edu.cn (Q.Z.); \\ douww@zju.edu.cn (W.D.) \\ 2 College of Pharmaceutical Sciences, Zhejiang University, Hangzhou 310012, China; Y215190015@zju.edu.cn \\ * Correspondence: guanwj@zju.edu.cn; Tel.: +86-0571-88206477 \\ + These authors contributed equally to this work.
}

Citation: Zhao, S.; Guo, D.; Zhu, Q.; Dou, W.; Guan, W. Display of Microbial Glucose Dehydrogenase and Cholesterol Oxidase on the Yeast Cell Surface for the Detection of Blood Biochemical Parameters. Biosensors 2021, 11, 13. https://doi. org $/ 10.3390 /$ bios11010013

Received: 20 November 2020 Accepted: 28 December 2020 Published: 30 December 2020

Publisher's Note: MDPI stays neutral with regard to jurisdictional clai$\mathrm{ms}$ in published maps and institutional affiliations.

Copyright: $\odot 2020$ by the authors. Licensee MDPI, Basel, Switzerland. This article is an open access article distributed under the terms and conditions of the Creative Commons Attribution (CC BY) license (https:// creativecommons.org/licenses/by/ $4.0 /)$.

\begin{abstract}
High levels of blood glucose are always associated with numerous complications including cholesterol abnormalities. Therefore, it is important to simultaneously monitor blood glucose and cholesterol levels in patients with diabetes during the management of chronic diseases. In this study, a glucose dehydrogenase from Aspergillus oryzae TI and a cholesterol oxidase from Chromobacterium sp. DS-1 were displayed on the surface of Saccharomyces cerevisiae, respectively, using the yeast surface display system at a high copy number. In addition, two whole-cell biosensors were constructed through the immobilization of the above yeast cells on electrodes, for electrochemical detection of glucose and cholesterol. The assay time was $8.5 \mathrm{~s}$ for the glucose biosensors and $30 \mathrm{~s}$ for the cholesterol biosensors. Under optimal conditions, the cholesterol biosensor exhibited a linear range from 2 to $6 \mathrm{mmol} \cdot \mathrm{L}^{-1}$. The glucose biosensor responded efficiently to the presence of glucose at a concentration range of $20-600 \mathrm{mg} \cdot \mathrm{dL}^{-1}\left(1.4-33.3 \mathrm{mmol} \cdot \mathrm{L}^{-1}\right)$ and showed excellent anti-xylose interference properties. Both biosensors exhibited good performance at room temperature and remained stable over a three-week storage period.
\end{abstract}

Keywords: whole-cell biosensor; yeast surface display; cholesterol oxidase; glucose dehydrogenase; electrochemical detection

\section{Introduction}

Diabetes is currently a global epidemic with over 400 million cases and the prevalence of which is rapidly increasing [1,2]. The disease is associated with numerous complications, especially cardiovascular diseases. Indices of blood cholesterol are often used as the thresholds for risk assessment and guides to therapy [3-5]. Therefore, effective monitoring of blood glucose and cholesterol plays a crucial role in the management of diabetes. Currently, large biochemical analyzers are the mainstream methods of detecting diabetes related blood parameters in clinical practice [6-8]. However, the approach requires specialized instruments and complicated experimental procedures [9] although it is highly reliable and gives high precision. With increasing demand for point-of-care testing (POCT), biosensors have been proposed as an attractive alternative as they are quick, convenient and economically feasible [10]. Among them, the optical and electrochemical based POCT biosensors gradually become the leader choices [11]. Because significant turbidity of most real samples and strong light from environment always bring errors, the detection accuracy of optical biosensors is easily interfered [12]. Hence, electrochemical biosensors are more favorable in practical applications [13]. At present, the most well-known brands of glucose POCT biosensors based on electrochemical technology on the market are Roche, Johnson \& Johnson, Bayer, Abbott, et al. 
Enzyme-based biosensors represent the most popular group of electrochemical biosensors currently available [14]. Notably, glucose oxidase or glucose dehydrogenase is the most widely used enzyme for glucose detection $[15,16]$. Glucose dehydrogenase forms a complex with cofactors such as flavin adenine dinucleotide (FAD), nicotinamide adenine dinucleotide (NAD), or pyrroloquinoline quinone (PQQ) [17]. Compared with glucose oxidase and other kinds of glucose dehydrogenases, the FAD-dependent glucose dehydrogenase, predominantly found in Aspergillus, has obvious sensing advantages due to its favorable substrate specificity and insensitivity to oxygen [18]. On the other hand, cholesterol oxidase, which is a FAD-dependent oxidoreductase derived from bacteria, is most widely utilized for the detection of cholesterol [19]. Nonetheless, the high cost of purification and poor stability of the free enzymes still present a challenge for the large-scale production and practical application of these enzyme-based biosensors [20]. Therefore, electrochemical whole-cell biosensors based on the surface display technology have been the focus of several studies since they may provide an effective way of overcoming the challenges associated with their enzyme-based counterparts [21].

Surface display is a powerful technology that allows the presentation of multiple proteins on the surface of microbes such as bacteria and yeast [22]. For instance, previous studies displayed a Bacillus subtilis derived NAD-dependent glucose dehydrogenase and its mutants on the surface of Escherichia coli using the ice nucleation protein (INP) as an anchoring motif $[23,24]$. However, no report currently exists on microbial cell-surface display of cholesterol oxidase. The yeast surface display (YSD) system is more advantageous in displaying complex eukaryotic proteins which require post-translational modification or have high molecular mass [25]. The most common yeast display system, pioneered by Boder and Wittrup, employs the Aga1 and Aga2 subunits of a-agglutinin to anchor the target enzymes onto the cell wall of Saccharomyces cerevisiae [26]. The anchoring of enzymes on the yeast cell surface allows for direct enzymatic reaction with substrates without the need for purification of enzymes and this can significantly reduce the cost of preparation as well as application of enzyme-based biosensors [27]. Moreover, the surface of yeast cells provides a biocompatible microenvironment that helps in maintaining the stability of enzymes [28]. The above advantages indicate that displaying glucose dehydrogenase and cholesterol oxidase on the surface of yeast cells may potentially be useful in the development of electrochemical biosensing platforms for the detection of blood glucose and cholesterol.

In this study, a FAD-dependent glucose dehydrogenase gene from Aspergillus oryzae TI [29] and a cholesterol oxidase gene from Chromobacterium sp. DS-1 [30] were cloned and the corresponding enzymes were displayed on the surface of S. cerevisiae through the Aga1Aga2 system, respectively. Afterwards, the enzyme-displayed yeast cells were immobilized onto electrodes to construct electrochemical biosensors for the detection of glucose and cholesterol. The catalytic activity of the surface-displayed enzymes was measured carefully and the performance of the two related biosensors was evaluated subsequently. The results demonstrated that this strategy had the advantages of simplicity, economic feasibility, and stability in the application of glucose and cholesterol biosensors.

\section{Materials and Methods}

\subsection{Strains, Media and Reagents}

The strains used in this study are described in Table S1. E. coli TG1 [31] was used for recombinant DNA manipulations and was cultured in Luria-Bertani (LB) medium at $37^{\circ}$ C. S. cerevisiae EBY100 [26] was obtained from Ziyun Biotech (Hangzhou, Zhejiang, China) and used for yeast cell surface display. The S. cerevisiae EBY100 was first grown in a seed medium containing $0.67 \%$ yeast nitrogen base, $0.5 \%$ casamino acid and $2 \%$ glucose before being transferred into the induction medium for surface display of the enzymes. The composition of induction medium was the same as that of the seed medium only that glucose was replaced with galactose. The protein expression was induced at $20^{\circ} \mathrm{C}$ with continuous shaking at $220 \mathrm{rpm}$. Restriction enzymes were purchased from Takara Bio 
(Shiga, Japan) while all the other biochemical reagents were of at least analytical grade and purchased from Merck (Darmstadt, Germany), Sangon Biotech (Shanghai, China), Aladdin (Shanghai, China) or Sinopharm Chemical Reagent (Shanghai, China).

\subsection{Construction of Vectors}

All the vectors used in this study are listed in Table S1. The cholesterol oxidase gene derived from Chromobacterium sp. DS-1 (named CHO1, Sequence ID: AB456533.1) and glucose dehydrogenase gene derived from Aspergillus oryzae TI (named GDH1, Sequence ID: XM_002372558.1) were codon optimized and synthesized by Generay Biotech (Shanghai, China). To construct the vectors pYD1-CHO1 and pYD1-GDH1, the synthetic genes were digested with $B a m \mathrm{HI}$ and $E c o$ RI before being ligated into the multiple cloning site of vector pYD1 [32]. In addition, the extended linkers were prepared by annealing synthetic complementary single-stranded DNAs of the target sequences followed by PCR. The linkers added one or two proline-alanine-serine (PAS) sequences (ASPAAPAPASPAAPAPSAPA) to the original GS linker (GGGGSGGGGSGGGGS) in pYD1-CHO1. Thereafter, the amplification products were cloned into the HindIII and BamHI sites of vector pYD1-CHO1

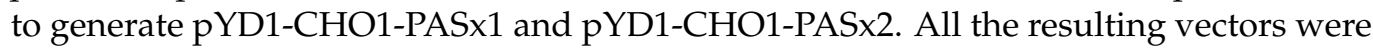
verified through PCR and sequencing.

\subsection{Freeze-Drying of Yeast Cells}

After induction, the enzyme-displayed yeast cells harboring vector pYD1-CHO1 or pYD1-GDH1 were harvested through centrifugation, washed with $1 \times$ phosphate buffered saline (PBS, pH 7.4) and resuspended in the cryoprotectant buffer which consisted of $1 \times$ PBS and $5 \%$ glycerol. Afterwards, the cell suspensions were freeze-dried using a freeze dryer (LGJ-10, Henan Brother Equipment Co., Ltd., Zhengzhou, China). The freeze-dried cell samples were then stored at $4{ }^{\circ} \mathrm{C}$ for later use.

\subsection{Enzyme Activity Assays}

Glucose dehydrogenase activity of the Gdh1-displayed yeast cells was assessed using 2,6-dichlorophenol-indophenol (DCPIP) and phenazine methosulfate (PMS) according to a previously published protocol [33]. Briefly, the working solution was configured, and the final concentration of glucose was $201 \mathrm{mmol} \cdot \mathrm{L}^{-1} .1 .5 \mathrm{~mL}$ of the working solution was equilibrated at $37^{\circ} \mathrm{C}$ for about $5 \mathrm{~min}$, and then the $20 \mathrm{OD}_{600}$ freeze-dried cell samples were resuspended in this solution to initiate the reaction. During a 5-min reaction, a decrease in the optical density of the supernatant was measured at $600 \mathrm{~nm}$ using a spectrophotometer, with water as the reference. Finally, change in absorbance per minute was used to calculate enzyme activity.

Cholesterol oxidase activity of the Cho1-displayed yeast cells was determined through the oxidative coupling of 4-aminoantipyrine and phenol as previously described [34]. Configuration of the working solution was performed according to this method and the final concentration of cholesterol in the solution was $0.89 \mathrm{mmol} \cdot \mathrm{L}^{-1}$. After incubating the $1.5 \mathrm{~mL}$ working solution at $37^{\circ} \mathrm{C}$ for $5 \mathrm{~min}$, the $20 \mathrm{OD}_{600}$ freeze-dried cell samples were resuspended with this solution to start the reaction. The amount of $\mathrm{H}_{2} \mathrm{O}_{2}$ catalyzed by cholesterol oxidase was then calculated by measuring the increase in $\mathrm{OD}_{500}$ of the supernatant per minute, to define the value of enzyme activity.

\subsection{Fabrication of the Whole-Cell Biosensors}

The biosensor used in this study consisted of a two-electrode system made from carbon paste or gold. The carbon paste-based two-electrode strips were formed by successively printing silver ink, carbon ink and insulating ink on a polyethylene terephthalate (PET) material through the screen-printing technique. The gold two-electrode strips were purchased from Jinhong Technology (Beijing, China). The size of the reaction chamber for each two-electrode strip was $5 \mathrm{~mm}$ long, $1.95 \mathrm{~mm}$ wide and $0.125 \mathrm{~mm}$ high. The $20 \mathrm{OD}_{600}$ freeze-dried YSD cells were resuspended in $50 \mu \mathrm{L}$ of the respective buffers before adding 
$0.05 \mathrm{~g}$ of FAD to mix. The YSD cell solution and electrochemical solution which contained microcrystalline cellulose, polyvinylpyrrolidone, octyl polyethylene glycol phenyl ether, phenazine ethosulfate, trehalose and the electron mediator (potassium ferricyanide or hexaammineruthenium (III) chloride), were mixed in a ratio of 1:4. The reaction chamber of each two-electrode strip was spotted with $1 \mu \mathrm{L}$ of the above mixed solution and dried at $30{ }^{\circ} \mathrm{C}$ for $20 \mathrm{~min}$. In theory, each resulting biosensor contained approximately $0.08 \mathrm{OD}_{600}$ YSD cells. The mechanism of detection is described in Figure S1, and a schematic illustration of the reaction chamber is shown in Figure S2. Performance of the screen-printed carbon electrodes was evaluated before the formal testing (Figure S3).

\subsection{Preparation of Whole Blood Samples}

Whole blood samples were collected into sodium heparin tubes to prevent hemolysis. The initial hematocrit (HCT) was determined by testing the volume of plasma and red blood cells after centrifugation before adjusting it to $42 \%$ by adding or removing plasma. The initial concentration of glucose in whole blood samples was measured using a YSI glucose analyzer (YSI2300, YSI Life Sciences, Yellow Springs, OH, USA). Glucose solutions were supplemented to obtain the desired concentrations in whole blood samples.

\subsection{Electrochemical Measurements}

All electrochemical measurements were performed using an electrochemical workstation (CHI660E, CH Instruments, Shanghai, China) or a portable electrochemical monitor (305A, Jiangsu Yuyue Medical Instruments Co., Ltd., Jiangsu, China). Amperometric method, in which a constant potential was applied to the working electrode and the current was measured after a certain reaction time, was used in this work. For the glucose biosensor, a DC voltage of $0.3 \mathrm{~V}$ was applied on the working electrode for $8.5 \mathrm{~s}$ and a final current value at $8.5 \mathrm{~s}$ was read for data analysis. In addition, for the cholesterol biosensor, a DC voltage of $0.3 \mathrm{~V}$ was applied on the working electrode for $30 \mathrm{~s}$ and a final current value at $30 \mathrm{~s}$ was used for data analysis.

\section{Results}

\subsection{Surface Display of Glucose Dehydrogenase}

Previous reports suggested that the glucose dehydrogenase derived from Aspergillus oryzae TI is a FAD-dependent oxidoreductase, which has the characteristics of high substrate specificity against glucose, excellent thermal stability and is not affected by dissolved oxygen [29]. This enzyme is composed of 593 amino acids, including a signal peptide ranging from 1-22 amino acids at the N-terminus [35]. To display Gdh1 on the surface of yeast, the signal peptide truncated gene sequence (1713 bp) of Gdh1 was synthesized according to the codon preference in S. cerevisiae and introduced into the multiple cloning site of vector $\mathrm{pYD1}$. The resulting vector $\mathrm{pYD1-GDH1}$ carrying the AGA2-GDH1 fusion gene (Figure 1a) was then transformed into S. cerevisiae EBY100, which harbored Aga1 as a cell wall anchoring motif, to generate the G1 strain (Figure 1b). The expression of $A G A 1$ as well as $A G A 2$ was driven by the galactose-inducible GAL1 promoter. The G1 strain was cultured in a $2 \%$ glucose medium to the mid-logarithmic growth phase, and then was transferred to a $2 \%$ galactose medium to induce the persistent expression of Gdh1. Afterwards, the G1 yeast cells were collected at the end of fermentation and freeze dried. 

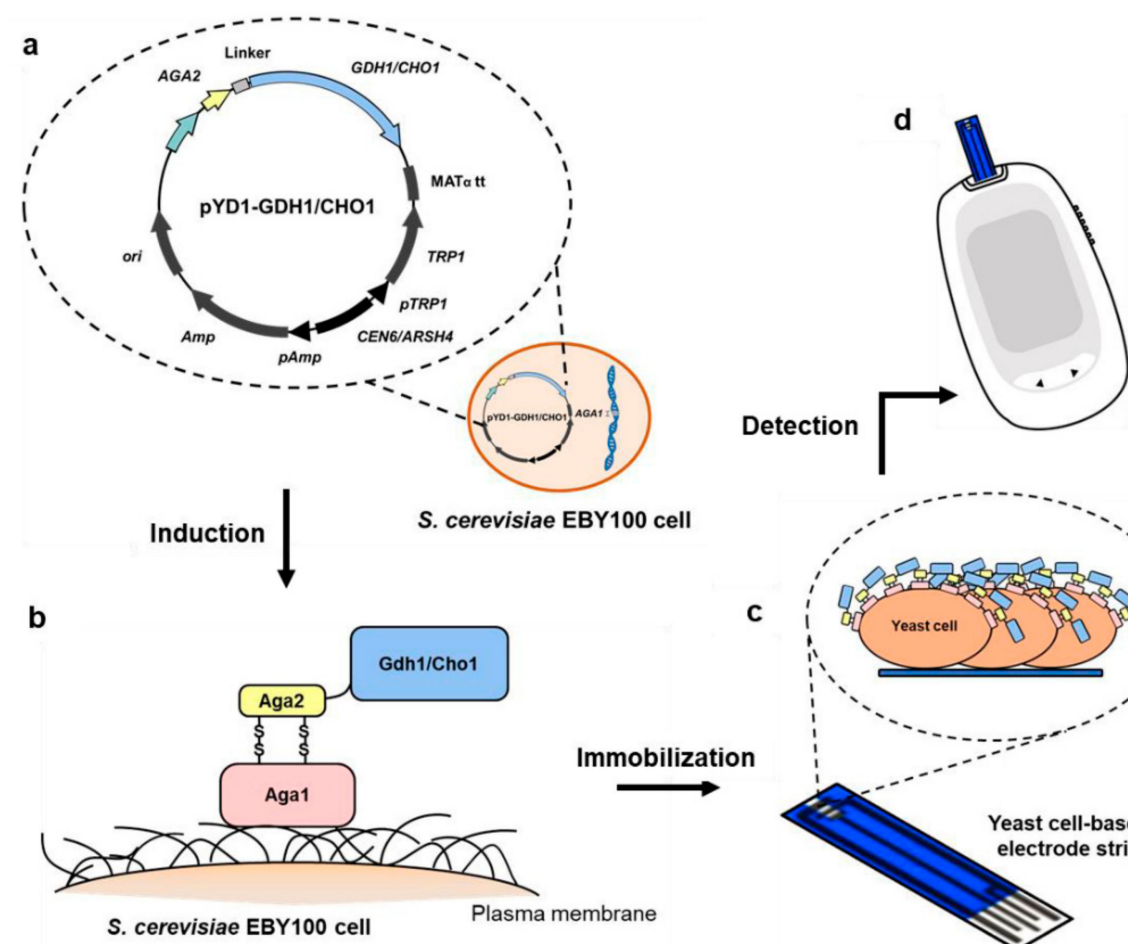

C

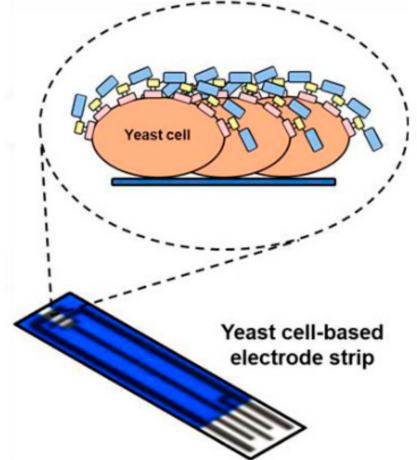

Figure 1. The strategy for constructing the surface-displayed glucose and cholesterol biosensors. (a) A map of the pYD1-GDH1 or pYD1-CHO1 vector. The enzyme Gdh1 or Cho1 (blue) was expressed as a C-terminal fusion to the Aga2 subunit of a-agglutinin (yellow) and connected by a linker (grey). (b) Displaying Gdh1 or Cho1 on the surface of yeast. The inducing Aga2 subunit associates with the a-agglutinin Aga1 subunit through two disulfide bonds. The Aga2-enzyme fusion protein was subsequently secreted to the extracellular space where Aga1 could be anchored to the cell wall through $\beta$-1, 6-glucan covalent linkage. (c) Fabrication of the whole-cell biosensors by immobilizing the YSD cells. (d) Electrochemical detection of glucose or cholesterol using a portable electrochemical monitor.

Maximum catalytic activity $\left(0.7 \mathrm{U}\right.$ per $\mathrm{OD}_{600}$ cells) of the surface-displayed Gdh1 was observed after $48 \mathrm{~h}$ of galactose induction (Figure $2 \mathrm{a}$ ). Therefore, $48 \mathrm{~h}$ was selected as the optimal induction time for the G1 strain and used for subsequent experiments. The effect of temperature, $\mathrm{pH}$ and storage time on the activity of Gdh1 was also evaluated. The results showed that Gdh1 was active from 10 to $60{ }^{\circ} \mathrm{C}$ and the activity reached a peak at $30{ }^{\circ} \mathrm{C}$. In addition, the enzyme retained over $95 \%$ of its activity from $20{ }^{\circ} \mathrm{C}$ to $40{ }^{\circ} \mathrm{C}$, indicating that it had good thermal stability and could be applied over a broad range of temperature (Figure $2 \mathrm{~b}$ ). The optimum $\mathrm{pH}$ for Gdh1 activity was observed to be 7.0. More than $75 \%$ of Gdh1 activity was maintained within the $\mathrm{pH}$ range of $6.5-7.5$ (Figure 2c). However, the storage stability of the surface-displayed Gdh1 appeared to be limited. Activity of the enzyme began to decrease following storage at $4{ }^{\circ} \mathrm{C}$ for one week and retained just $20 \%$ of the initial activity after 3 weeks of storage (Figure $2 \mathrm{~d}$ ). This implied that the subsequent immobilization process should be performed as soon as possible after obtaining the freeze-dried G1 strain cells to avoid the loss of enzyme activity. 

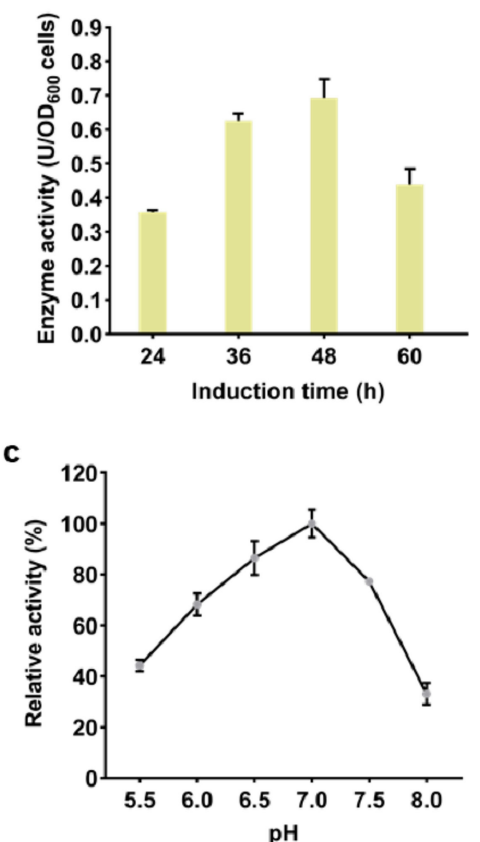
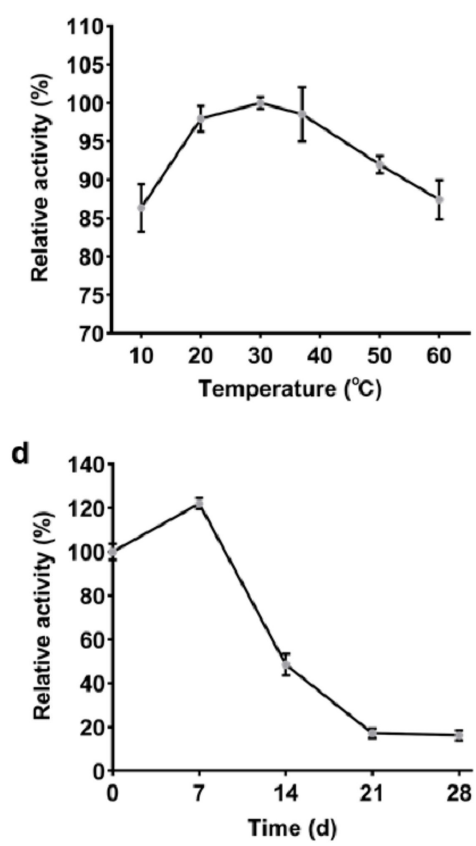

Figure 2. Determination of the catalytic activity of surface-displayed Gdh1. (a) Activity of the surfacedisplayed Gdh1 at different time points after galactose induction. (b-d) Effect of (b) temperature, (c) $\mathrm{pH}$, and (d) storage time on the activity of Gdh1. Error bars indicate the SD of samples tested in triplicate.

\subsection{Development of an Electrochemical Glucose Biosensor Based on the Surface-Displayed Gdh1}

To develop a whole-cell glucose biosensor, the freeze-dried G1 yeast cells $\left(0.08 \mathrm{OD}_{600}\right.$ cells per strip) with different artificial electron mediators and buffer solutions, were immobilized on the surface of screen-printed carbon electrodes. Electrochemical detection was then performed. Although the glucose biosensors exhibited a similar slope of the concentration-response current curve when different electron mediators were used, the glucose biosensor using hexaammineruthenium (III) chloride as electron mediator presented lower background current than that of potassium ferricyanide (Figure 3a). In addition, the impact of phosphate buffer, heppso-malic acid buffer and fumaric acid buffer was evaluated to examine which one of them was better suited for the glucose biosensor. The results showed that the biosensor based on the $0.1 \mathrm{~mol} \cdot \mathrm{L}^{-1}$ phosphate buffer ( $\mathrm{pH} 7.0$ ) system had a greater response current at a higher glucose concentration (Figure 3b). Consequently, under optimized electrode conditions, the biosensor was employed for the detection of glucose with successive additions. The linear detection range of the glucose biosensor was $20-600 \mathrm{mg} \cdot \mathrm{dL}^{-1}\left(1.4-33.3 \mathrm{mmol} \cdot \mathrm{L}^{-1}\right)$ and the testing sensitivity was shown to be $25 \mathrm{mg} \cdot \mathrm{dL}^{-1}$ at the concentration range of 20 to $600 \mathrm{mg} \cdot \mathrm{dL}^{-1}$ (Figure $3 \mathrm{c}, \mathrm{d}$ ).

Xylose is the most common interferent to biosensors using glucose dehydrogenase. Therefore, the study examined the selectivity of the optimized glucose biosensor by adding extra xylose into the glucose substrate solution. Addition of xylose had almost no impact on the biosensor developed by this study. However, the biosensor immobilized with commercial FAD-dependent glucose dehydrogenase (581 U. $\mathrm{mg}^{-1}$, Code: GLD-361, Toyobo Co., Ltd., Osaka, Japan) was affected substantially. $189 \%$ and $29 \%$ of additional interference current was generated in $70 \mathrm{mg} \cdot \mathrm{dL}^{-1}$ and $300 \mathrm{mg} \cdot \mathrm{dL}^{-1}$ of glucose substrate solution after adding $90 \mathrm{mg} \cdot \mathrm{dL}^{-1}$ of xylose respectively (Figure 3e). This indicated that the optimized glucose biosensor had a good ability to get rid of xylose interference and great potential for practical application.

The biosensors were stored at room temperature for 21 days and changes in current responses towards $280 \mathrm{mg} \cdot \mathrm{dL}^{-1}$ of glucose were measured. The findings revealed that the biosensors retained $79 \%$ of the initial response current after storage for 21 days (Figure 3f). 
Furthermore, the biosensor was used to determine the concentration of glucose in whole blood samples to explore the possibility of clinical application. The results showed that the linear response range of the biosensor to glucose in whole blood samples was 20$600 \mathrm{mg} \cdot \mathrm{dL}^{-1}$ (Figure 3g). Although at present the accuracy of the glucose biosensor did not completely meet the requirements of the standard [36], it exhibited the potential of detecting real samples (Supplementary Figure S4, Table S3).

a

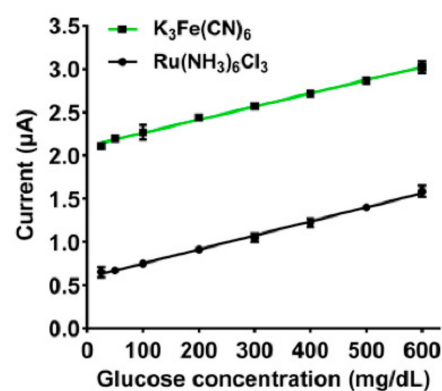

e

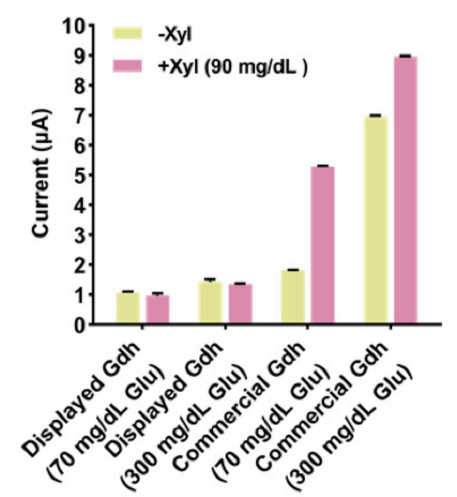

b

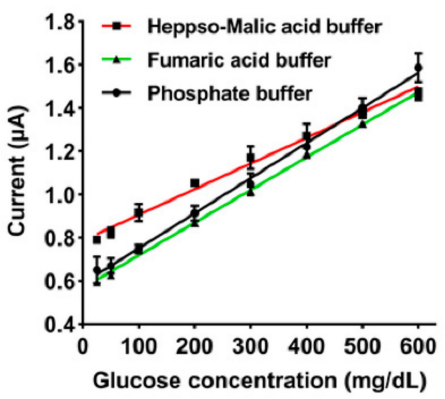

f

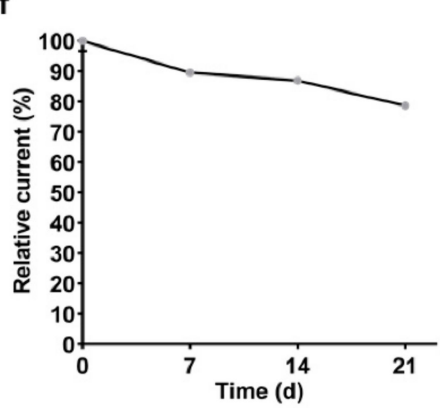

C

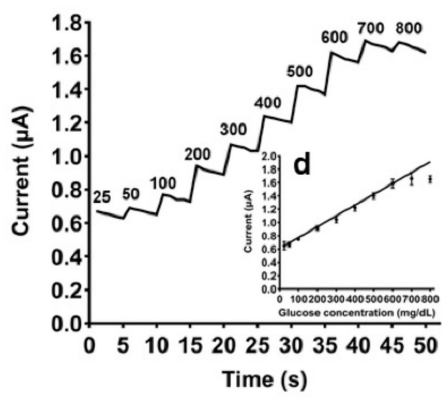

g

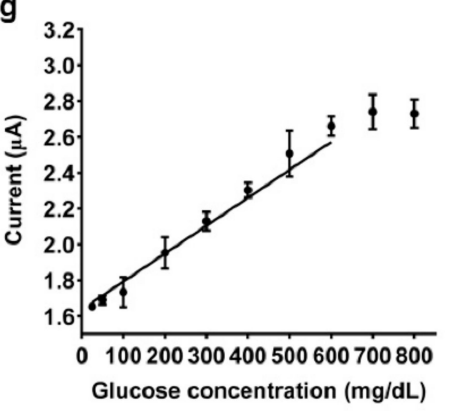

Figure 3. Characterization of the whole-cell glucose biosensor. Effect of (a) electron mediator and (b) buffer on the glucose biosensor. (c) Amperometric response for successive addition of 25, 50 and $100 \mathrm{mg} \cdot \mathrm{dL}^{-1}$ of glucose. (d) The plot of linear regression. The (e) anti-xylose performance and (f) storage stability of the optimized glucose biosensor. (g) The response current of the optimized biosensor to glucose in whole blood samples. Electrochemical detection parameters: voltage $0.3 \mathrm{~V}$, acquisition time $8.5 \mathrm{~s}$. Error bars indicate the SD of samples tested in triplicate.

\subsection{Surface Display of Cholesterol Oxidase}

The strategy for developing a glucose biosensor based on YSD cells proved to be feasible and showed potential for practical application in monitoring glucose levels in whole blood samples. Therefore, the study used a similar approach for the detection of cholesterol. Previous studies reported that the cholesterol oxidase derived from Chromobacterium sp. DS-1 had favorable protein structural characteristics [37], excellent stability [30] and high enzyme activity [38]. This enzyme consists of 584 amino acids with the first 44 being a signal peptide [38]. In the present study, the codon optimized gene sequence (1620 bp) encoding Cho1 without the signal peptide was synthesized and the resulting vector pYD1-CHO1 was constructed (Figure 1a). Thereafter, pYD1-CHO1 was transformed into $S$. cerevisiae EBY100 to generate the C1 strain, which successfully displayed Cho1 on the surface of yeast (Figure 1b). It was observed that the C1 strain had a significantly lower growth rate compared with the G1 strain or the P1 strain containing the empty vector pYD1. This implied that displaying Cho1 on the surface might impose a growth burden to the cells (Figure S5).

The optimal induction time for the $\mathrm{C} 1$ strain was shown to be $36 \mathrm{~h}$, at which enzyme activity reached the maximum value of $3.4 \times 10^{-3} \mathrm{U}$ per $20 \mathrm{OD}_{600}$ freeze-dried cells in vitro 
(Figure 4a). The optimum reaction temperature for the surface-displayed Cho1 was also found to be $30{ }^{\circ} \mathrm{C}$. More than $60 \%$ of its activity occurred between $20^{\circ} \mathrm{C}$ and $40{ }^{\circ} \mathrm{C}$, while about $18 \%$ activity was retained at $60{ }^{\circ} \mathrm{C}$ (Figure $4 \mathrm{~b}$ ). Cho1 had an optimum pH of 6.5 and over $50 \%$ of its activity occurred in the $\mathrm{pH}$ range of 5.5 to 7.5 (Figure $4 \mathrm{c}$ ). Afterwards, the freeze-dried $\mathrm{C} 1$ strain cells were stored at $4{ }^{\circ} \mathrm{C}$ and their residual activity determined intermittently within a one-month period, to investigate the stability of Cho1 in vitro. No significant decrease in activity was observed and approximately $95 \%$ of original enzyme activity could still be detected after the 4-week storage period. This suggested that the $\mathrm{C} 1$ strain cells had good storage stability (Figure 4 d).

a

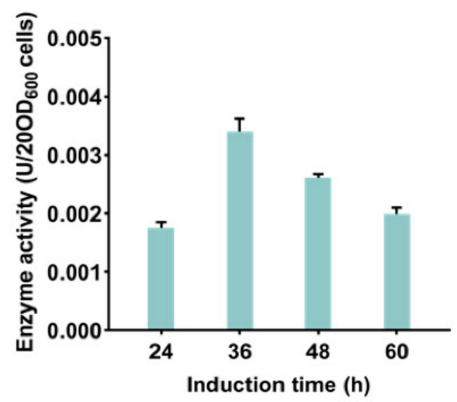

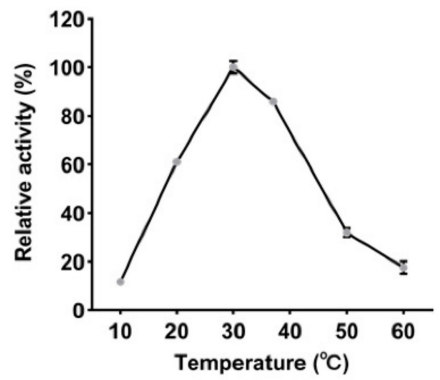

C

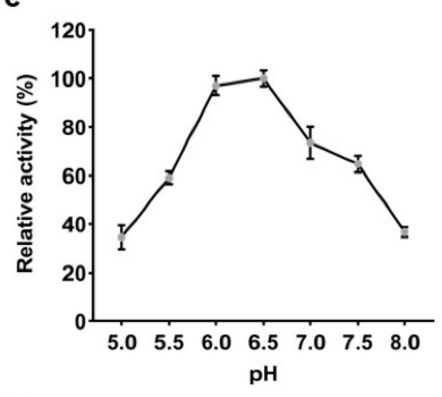

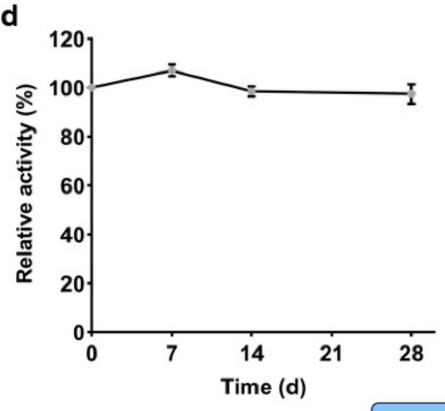
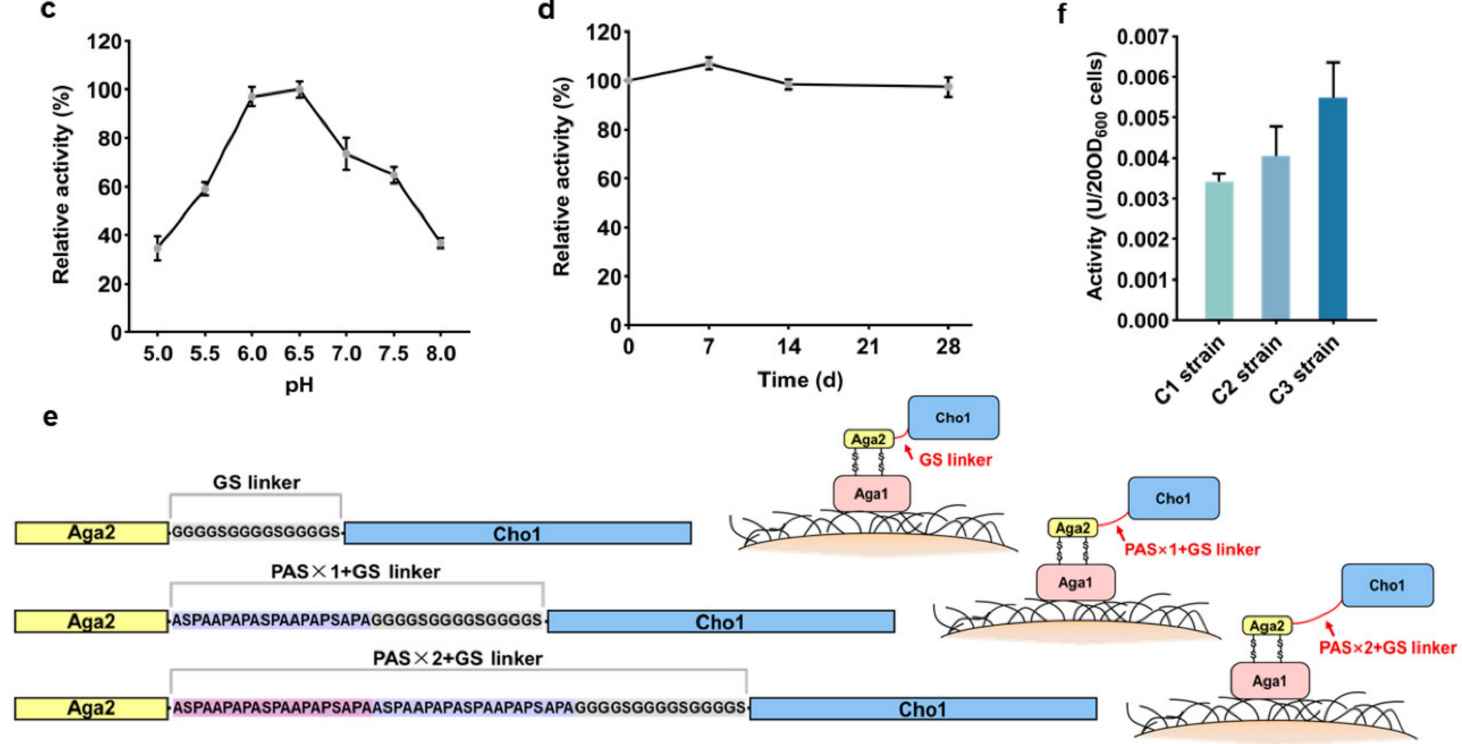

Figure 4. Determination of the catalytic activity of surface-displayed Cho1. (a) Activity of the displayed Cho1 at different time points after galactose induction. (b-d) Effect of (b) temperature, (c) $\mathrm{pH}$ and (d) storage time on the activity of Cho1. (e) Schematic representation of the linkers connecting Aga2 and Cho1. The original GS linker (GGGGSGGGGSGGGGS) was lengthened with one or two PAS sequences (ASPAAPAPASPAAPAPSAPA) to form the PAS $\times 1+$ GS and PAS $\times 2+$ GS linkers, respectively. (f) Activity of Cho1 with different linkers. Error bars indicate the SD of samples tested in triplicate.

The maximum activity of Cho1 was determined as $3.4 \times 10^{-3} \mathrm{U}$ per $20 \mathrm{OD}_{600}$ freezedried yeast cells and this was almost two orders of magnitude lower than that of Gdh1. This implied that the activity of surface-displayed Cho1 had a limited potential to meet the requirements for practical application. Therefore, an attempt was made to improve its activity by increasing the length of linker sequence, which was located between AGA2 and CHO1 in the pYD1-CHO1 vector. Based on previous reports, the original GS linker was modified by adding one or two PAS linkers, which consisted of 20 amino acids including proline, alanine and serine, with the advantages of being hydrophilic, uncharged and structureless $[39,40]$ (Figure 4e). The resulting vector pYD1-CHO1-PASx1 or pYD1-CHO1PASx2 was then transformed into S. cerevisiae EBY100 to generate the C2 or C3 strains, 
respectively. The results showed that the displayed Cho1 with a PAS $\times 1+$ GS linker had a $19 \%$ increase in activity, while the one with a PAS $\times 2+$ GS linker exhibited a $62 \%$ increase, which was $5.5 \times 10^{-3}$ U per $20 \mathrm{OD}_{600}$ freeze-dried cells (Figure $4 \mathrm{f}$ ). Owing to the longer linkers, the displayed enzyme obtained a greater distance to leave the cell surface, hence had enough conformational space, resulting in a decrease in the loss of enzymatic activity.

\subsection{Development of an Electrochemical Cholesterol Biosensor Based on Surface-Displayed Cho1}

The freeze-dried $\mathrm{C} 3$ yeast cells $\left(0.08 \mathrm{OD}_{600}\right.$ cells per strip) with different artificial electron mediators and buffer solutions, were immobilized onto the surface of screen-printed carbon or gold electrodes, respectively, to develop a whole-cell cholesterol biosensor. Like that of the glucose biosensor, hexaammineruthenium (III) chloride had more advantages as an artificial electron mediator in this cholesterol biosensor, exhibiting a lower background current (Figure 5a). Moreover, the study compared the current response of the cholesterol biosensor in phosphate buffer, hepes buffer and TES buffer. As a result, the biosensor based on $0.1 \mathrm{~mol} \cdot \mathrm{L}^{-1}$ phosphate buffer ( $\mathrm{pH}$ 6.5) exhibited a smaller background current and a larger difference in response current from 2 to $6 \mathrm{~mol} \cdot \mathrm{L}^{-1}$ concentration of cholesterol (Figure $5 b$ ). In addition, using a gold electrode instead of a carbon paste one not only slightly improved the detection sensitivity of the cholesterol biosensor, but also contributed to the larger background current (Figure 5c).

a

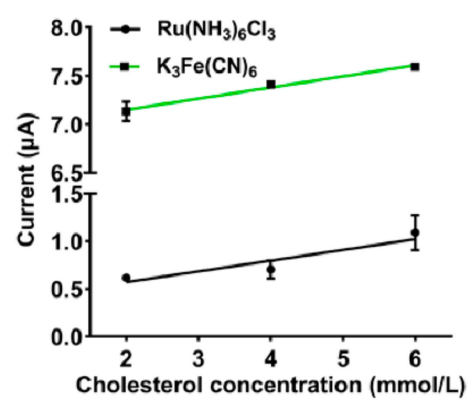

C

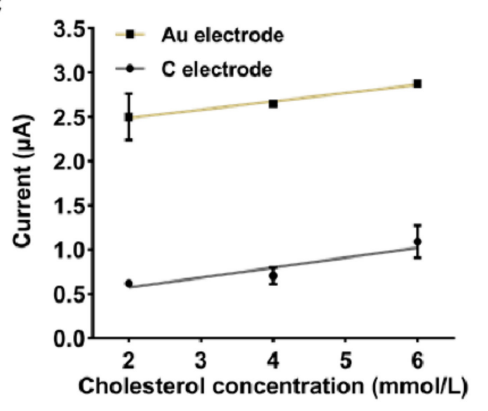

b

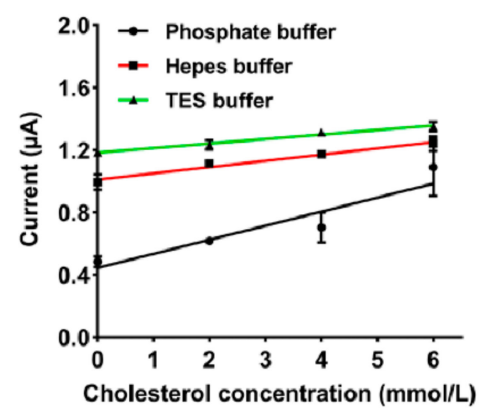

d

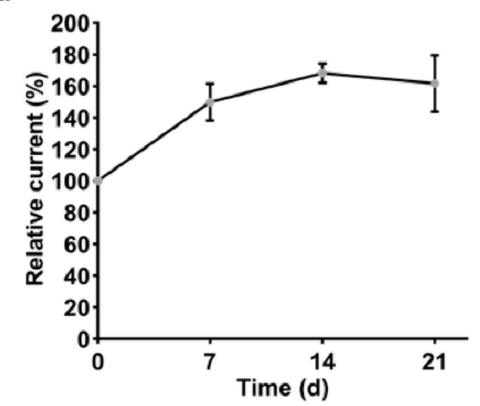

Figure 5. Characterization of the whole-cell cholesterol biosensor. (a-c) Effect of (a) electron mediator, (b) buffer and (c) electrode material on the cholesterol biosensor. (d) Storage stability of the optimized cholesterol biosensor. Electrochemical detection parameters: voltage $0.3 \mathrm{~V}$, acquisition time $30 \mathrm{~s}$. Error bars indicate the SD of samples tested in triplicate.

The cholesterol biosensors were stored at room temperature and the changes in current responses towards $4 \mathrm{mmol} \cdot \mathrm{L}^{-1}$ cholesterol were measured weekly to explore their storage stability. After 21 days of storage, the response currents of the biosensors began to gradually decrease, and the loss was less than $20 \%$ of the optimal response current (Figure $5 \mathrm{~d}$ ). It was also shown that the response currents of the biosensors increased during the first seven days of storage. 


\section{Discussion}

The advantage of a surface-displayed enzyme is that the costly protein purification step can be skipped, and stability is effectively improved. In this study, two whole-cell biosensors based on YSD were developed for the detection of glucose and cholesterol. The results showed that the optimized glucose biosensor had a broad detection linear range of 20-600 mg. $\mathrm{dL}^{-1}$ while that of the cholesterol biosensor was $2-6 \mathrm{mmol} \cdot \mathrm{L}^{-1}$. This indicated that the biosensors had a great potential for clinical application in the future. Additionally, the strategy presented here may provide insights on the development of other biosensors based on the cell surface display technology.

Although the cholesterol oxidase (Cho1) used in this study was reported to have outstanding activity (Supplementary Table S2), the surface-displayed Cho1 did not show the anticipated enzyme activity. This resulted to a relatively poor detection capability of the biosensor when compared with Gdh1, manifesting as a narrow linear range. Screening the highly active Cho1 mutants by directed evolution offers an available approach to problem solving [41]. It is still unclear why displaying Cho1 on the surface of yeast resulted to slow growth of the $\mathrm{C} 1$ strain although this may have been responsible for its low activity (Supplementary Figure S5). Moreover, given that Cho1 was obtained from a bacterium (Chromobacterium sp. DS-1) but displayed on the surface of a fungus (S. cerevisiae), the mismatched protein folding system might have resulted to partial misfolding of Cho1 and subsequently low activity. Therefore, the identification of a highly active cholesterol oxidase from a fungus should be the focus of future studies.

Since yeast cells occupy more space, the amount of surface-displayed enzyme immobilized on the electrode surface was limited, leading to a lower response current compared to the purified enzymes (Figure 3e). Consequently, crushing the cells to collect pieces of the cell wall and directly immobilize them onto the surface of the electrode might solve this problem and will be the focus of future research.

Supplementary Materials: The following are available online at https:/ / www.mdpi.com/2079-637 4/11/1/13/s1, Table S1: Strains and vectors used in this study, Table S2: Comparison of different cholesterol oxidases reported previously, Table S3: Accuracy evaluation of the glucose biosensor, Figure S1: The detection mechanism of glucose or cholesterol biosensor, Figure S2: Schematic diagram of the reaction chamber of the electrode strips, Figure S3: Performance evaluation of the screenprinted carbon electrodes, Figure S4: Accuracy evaluation of the glucose biosensor, Figure S5: Growth curve of the P1, G1 and C1 strains in the induction medium containing 2\% galactose.

Author Contributions: Conceptualization, W.G.; methodology, S.Z. and D.G.; validation, S.Z. and D.G.; formal analysis, S.Z. and D.G.; investigation, S.Z., D.G., Q.Z., and W.D.; data curation, S.Z. and D.G.; writing-original draft preparation, W.G. and S.Z.; writing—review and editing, W.G. and S.Z.; supervision, W.G. All authors have read and agreed to the published version of the manuscript.

Funding: This research was funded by National Key Research and Development Program of China (2019YFA0905400).

Institutional Review Board Statement: Not applicable.

Informed Consent Statement: Not applicable.

Data Availability Statement: Not applicable.

Conflicts of Interest: The authors declare no conflict of interest.

\section{References}

1. World Health Organization (WHO). Global Report on Diabetes; WHO: Geneva, Switzerland, 2016.

2. Cho, N.; Shaw, J.; Karuranga, S.; Huang, Y.; Fernandes, J.D.R.; Ohlrogge, A.; Malanda, B. IDF Diabetes Atlas: Global estimates of diabetes prevalence for 2017 and projections for 2045. Diabetes Res. Clin. Pract. 2018, 138, 271-281.

3. Levelt, E.; Rodgers, C.T.; Clarke, W.T.; Mahmod, M.; Ariga, R.; Francis, J.M.; Liu, A.; Wijesurendra, R.S.; Dass, S.; Sabharwal, N.; et al. Cardiac energetics, oxygenation, and perfusion during increased workload in patients with type 2 diabetes mellitus. Eur. Heart J. 2016, 37, 3461-3469. 
4. Anderson, T.J.; Grégoire, J.; Pearson, G.J.; Barry, A.R.; Couture, P.; Dawes, M.; Francis, G.A.; Genest, J.; Grover, S.; Gupta, M.; et al. 2016 Canadian Cardiovascular Society guidelines for the management of dyslipidemia for the prevention of cardiovascular disease in the adult. Can. J. Cardiol. 2016, 32, 1263-1282.

5. Grundy, S.M.; Stone, N.J.; Bailey, A.L.; Beam, C.; Birtcher, K.K.; Blumenthal, R.S.; Braun, L.T.; de Ferranti, S.; Faiella-Tommasino, J.; Forman, D.E.; et al. 2018 AHA/ACC/AACVPR/AAPA/ABC/ACPM/ADA/AGS/APhA/ASPC/ NLA/PCNA guideline on the management of blood cholesterol: Executive summary. J. Am. Coll. Cardiol. 2019, 73, 3168.

6. Chen, Y.; Liu, Q.; Yong, S.; Lee, T.K. High accuracy analysis of glucose in human serum by isotope dilution liquid chromatographytandem mass spectrometry. Clin. Chim. Acta 2012, 413, 808-813. [PubMed]

7. Qureshi, R.N.; Kaal, E.; Janssen, H.-G.; Schoenmakers, P.J.; Kok, W.T. Determination of cholesterol and triglycerides in serum lipoproteins using flow field-flow fractionation coupled to gas chromatography-mass spectrometry. Anal. Chim. Acta 2011, 706, 361-366. [PubMed]

8. Reinicke, M.; Schröter, J.; Müller-Klieser, D.; Helmschrodt, C.; Ceglarek, U. Free oxysterols and bile acids including conjugatesSimultaneous quantification in human plasma and cerebrospinal fluid by liquid chromatography-tandem mass spectrometry. Anal. Chim. Acta 2018, 1037, 245-255. [PubMed]

9. Li, L.; Dutkiewicz, E.; Huang, Y.; Zhou, H.; Hsu, C. Analytical methods for cholesterol quantification. J. Food Drug Anal. 2019, 27, 375-386. [PubMed]

10. Luppa, P.B.; Bietenbeck, A.; Beaudoin, C.; Giannetti, A. Clinically relevant analytical techniques, organizational concepts for application and future perspectives of point-of-care testing. Biotechnol. Adv. 2016, 34, 139-160.

11. Gauglitz, G. Point-of-care platforms. Annu. Rev. Anal. Chem. 2014, 7, 297-315.

12. Derina, K.; Korotkova, E.; Barek, J. Non-enzymatic electrochemical approaches to cholesterol determination. J. Pharm. Biomed. Anal. 2020, 191, 113538. [PubMed]

13. Putzbach, W.; Ronkainen, N.J. Immobilization techniques in the fabrication of nanomaterial-based electrochemical biosensors: A review. Sensors 2013, 13, 4811-4840. [PubMed]

14. Kucherenko, I.; Soldatkin, O.; Dzyadevych, S.; Soldatkin, A. Electrochemical biosensors based on multienzyme systems: Main groups, advantages and limitations-A review. Anal. Chim. Acta 2020, 1111, 114-131. [PubMed]

15. Bruen, D.; Delaney, C.; Florea, L.; Diamond, D. Glucose sensing for diabetes monitoring: Recent developments. Sensors 2017, 17, 1866.

16. Stolarczyk, K.; Rogalski, J.; Bilewicz, R. NAD(P)-dependent glucose dehydrogenase: Applications for biosensors, bioelectrodes, and biofuel cells. Bioelectrochemistry 2020, 135, 107574.

17. Narla, S.; Jones, M.; Hermayer, K.; Zhu, Y. Critical care glucose point-of-care testing. In Advances in Clinical Chemistry; Elsevier: Amsterdam, The Netherlands, 2016; Volume 76, pp. 97-121.

18. Okuda-Shimazaki, J.; Yoshida, H.; Sode, K. FAD dependent glucose dehydrogenases-Discovery and engineering of representative glucose sensing enzymes. Bioelectrochemistry 2020, 132, 107414.

19. Narwal, V.; Deswal, R.; Batra, B.; Kalra, V.; Hooda, R.; Sharma, M.; Rana, J.S. Cholesterol biosensors: A review. Steroids 2019, 143, 6-17.

20. Kirk, O.; Borchert, T.V.; Fuglsang, C.C. Industrial enzyme applications. Curr. Opin. Biotechnol. 2002, 13, 345-351.

21. Park, M. Surface display technology for biosensor applications: A review. Sensors 2020, 20, 2775.

22. Pham, M.-L.; Polakovič, M. Microbial cell surface display of oxidoreductases: Concepts and applications. Int. J. Biol. Macromol. 2020, 165, 835-841.

23. Liang, B.; Li, L.; Tang, X.; Lang, Q.; Wang, H.; Li, F.; Shi, J.; Shen, W.; Palchetti, I.; Mascini, M. Microbial surface display of glucose dehydrogenase for amperometric glucose biosensor. Biosens. Bioelectron. 2013, 45, 19-24. [CrossRef] [PubMed]

24. Liang, B.; Lang, Q.; Tang, X.; Liu, A. Simultaneously improving stability and specificity of cell surface displayed glucose dehydrogenase mutants to construct whole-cell biocatalyst for glucose biosensor application. Bioresour. Technol. 2013, 147, 492-498. [CrossRef] [PubMed]

25. Ueda, M. Yeast Cell Surface Engineering: Biological Mechanisms and Practical Applications; Springer: Singapore, 2019.

26. Boder, E.T.; Wittrup, K.D. Yeast surface display for screening combinatorial polypeptide libraries. Nat. Biotechnol. 1997, 15, 553-557. [CrossRef] [PubMed]

27. Shibasaki, S.; Maeda, H.; Ueda, M. Molecular display technology using yeast-Arming technology. Anal. Sci. 2009, 25, 41-49. [CrossRef] [PubMed]

28. Fan, S.; Liang, B.; Xiao, X.; Bai, L.; Tang, X.; Lojou, E.; Cosnier, S.; Liu, A. Controllable display of sequential enzymes on yeast surface with enhanced biocatalytic activity toward efficient enzymatic biofuel cells. J. Am. Chem. Soc. 2020, 142, 3222-3230. [CrossRef] [PubMed]

29. Omura, H.; Sanada, H.; Yada, T.; Morita, T.; Kuyama, M.; Ikeda, T.; Kano, K.; Tsujimura, S. Coenzyme-Binding Glucose Dehydrogenase. U.S. Patent 7,514,250, 7 April 2009.

30. Doukyu, N.; Shibata, K.; Ogino, H.; Sagermann, M. Purification and characterization of Chromobacterium sp. DS-1 cholesterol oxidase with thermal, organic solvent, and detergent tolerance. Appl. Microbiol. Biotechnol. 2008, 80, 59-70. [CrossRef]

31. Gibson, T. Studies on the Epstein-Barr Virus Genome; University of Cambridge: Cambridge, UK, 1984.

32. Kieke, M.C.; Cho, B.K.; Boder, E.T.; Kranz, D.M.; Wittrup, K.D. Isolation of anti-T cell receptor scFv mutants by yeast surface display. Protein Eng. 1997, 10, 1303-1310. [CrossRef] 
33. Kirmair, L.; Skerra, A. Biochemical analysis of recombinant AlkJ from Pseudomonas putida reveals a membrane-associated, flavin adenine dinucleotide-dependent dehydrogenase suitable for the biosynthetic production of aliphatic aldehydes. Appl. Environ. Microbiol. 2014, 80, 2468-2477. [CrossRef]

34. Allain, C.C.; Poon, L.S.; Chan, C.S.; Richmond, W.; Fu, P.C. Enzymatic determination of total serum cholesterol. Clin. Chem. 1974, 20, 470-475. [CrossRef]

35. Kitabayashi, M.; Tsuji, Y.; Kawaminami, H.; Kishimoto, T.; Nishiya, Y. Method for Highly Expressing Recombinant Glucose Dehydrogenase Derived from Filamentous Fungi. U.S. Patent 7,741,100, 22 June 2010.

36. International Organization for Standardization. In Vitro Diagnostic Test Systems-Requirements for Blood-Glucose Monitoring Systems for Self-Testing in Managing Diabetes Mellitus; ISO 15197; ISO: Geneva, Switzerland, 2013.

37. Sagermann, M.; Ohtaki, A.; Newton, K.; Doukyu, N. Structural characterization of the organic solvent-stable cholesterol oxidase from Chromobacterium sp. DS-1. J. Struct. Biol. 2010, 170, 32-40. [CrossRef]

38. Doukyu, N.; Shibata, K.; Ogino, H.; Sagermann, M. Cloning, sequence analysis, and expression of a gene encoding Chromobacterium sp. DS-1 cholesterol oxidase. Appl. Microbiol. Biotechnol. 2009, 82, 479. [CrossRef] [PubMed]

39. Schlapschy, M.; Binder, U.; Börger, C.; Theobald, I.; Wachinger, K.; Kisling, S.; Haller, D.; Skerra, A. PASylation: A biological alternative to PEGylation for extending the plasma half-life of pharmaceutically active proteins. Protein Eng. Des. Sel. 2013, 26, 489-501. [CrossRef] [PubMed]

40. Stern, L.A.; Schrack, I.A.; Johnson, S.M.; Deshpande, A.; Bennett, N.R.; Harasymiw, L.A.; Gardner, M.K.; Hackel, B.J. Geometry and expression enhance enrichment of functional yeast-displayed ligands via cell panning. Biotechnol. Bioeng. 2016, 113, 2328-2341. [CrossRef] [PubMed]

41. Qu, G.; Li, A.; Acevedo-Rocha, C.G.; Sun, Z.; Reetz, M.T. The crucial role of methodology development in directed evolution of selective enzymes. Angew. Chem. Int. Ed. 2019. [CrossRef] 